Jiun-Yan Tsai

Ji-Feng Ding

Gin-Shuh Liang

Kung-Don Ye

http://dx.doi.org/10.21278/brod69106

\title{
USE OF A HYBRID MCDM METHOD TO EVALUATE KEY SOLUTIONS INFLUENCING SERVICE QUALITY AT A PORT LOGISTICS CENTER IN TAIWAN
}

UDC 627.2:519.6

Original scientific paper

\begin{abstract}
Summary
The main purpose of this article is to develop a hybrid multiple criteria decision-making (MCDM) model to evaluate key solutions influencing service quality at a port logistics center in Taiwan. At first, this article proposes the use of a hybrid MCDM model incorporating the Analytic Hierarchy Process (AHP), Decision Making Trial and Evaluation Laboratory (DEMATEL), and Analytic Network Process (ANP) techniques to assess the causal relationships between criterion variables, including dependent relationships and feedback mechanisms. Then, using a hypothetical port logistics center case as an example, this study focuses port logistics center service quality solutions, and applies the hybrid MCDM model constructed in this article in order to explain its functioning and assessment procedures. Finally, via the various operating steps of the hybrid MCDM model, the key logistics center service quality solutions are ranked. Furthermore, some discussions and conclusion are provided in the last of this article.
\end{abstract}

Key words: $\quad$ multiple criteria decision-making (MCDM); Analytic Hierarchy Process (AHP); Decision Making Trial and Evaluation Laboratory (DEMATEL); Analytic Network Process (ANP); port logistics center

\section{Introduction}

Taiwan's economic activity chiefly revolves around international trade, and it is a typical foreign trade-dependent island country. In terms of volume and value, approximately $80 \%$ and $70 \%$ of Taiwan's international import/export cargo is shipped by means of the maritime transport chain [1], with the remaining portion being shipped by air. The relationship between international trade and Taiwan's economic development is consequently very close, and maritime transport plays an extremely important role in Taiwan's international trade and logistics activities.

In the maritime transport chain, ports are transshipment intermediaries between land and sea transport, and are also nodal points of cargo consolidation in the international trade 
and the logistics system [2]. During the 1990s, Taiwan's Kaohsiung port made active efforts to boost added service value in the maritime transport market [3, 4], and also use more effective operating methods to ship international cargo to all parts of the globe. As a result, by providing efficient logistics services platforms [5] and an effective marine terminal [6], Kaohsiung port was one of the most important maritime transport logistics centers in the Asia-Pacific region for a period of time $[1,2,7]$, and was the world's third largest container port in 1999. However, Taiwan currently faces severe competition from the cargo logistics markets of China, Northeast Asia, and Southeast Asia, and the surging cargo volume and geographical locations of ports in these regions are making them an ever-greater threat to Taiwan's ports. As a consequence, Kaohsiung port had fallen to only the world's $13^{\text {th }}$ largest container port in 2017. But as far as port transportation functions are concerned, we believe that the soft power issue on which Taiwan's international ports must focus their attention is their ability to deliver cargo safely and smoothly to destinations around the world via effective international port logistics centers $[4,8]$, which will facilitate international trade activity.

With today's increasingly stringent product and service requirements, the provision of products and services has gradually shifted from a focus on production and supply to a focus on customers' needs. And with the appearance of various quality management concepts and an operating environment in which consumers place much greater emphasis on service quality, the service quality at international port logistics centers has become a key factor in customers' port selection decisions $[4,9,10]$. Because service quality is a matter of customers' subjective perceptions and assessments, logistics service quality will have a positive influence on a logistics center's perceived operating performance [11-13], and port logistics centers must therefore place emphasis on service quality. And because perceived service quality can be equated with the gap between a customer's service expectations and that customer's assessment after receiving service $[14,15]$, whether service quality addresses customers' real needs is an urgent question for service providers. In this context, Liang et al. [9] has already investigated what factors influence a port logistics center's service quality (the question of "what"), and how to boost service quality (the question of "how"). They use the Quality Functional Deployment (QFD) method to investigate how logistics center operators can convert customers' service needs to solutions able to enhance service quality, and thereby seek out concrete, feasible plans for improving service quality. It is hoped that the findings of Liang et al. [9] can provide guidance to port logistics center operators assessing service quality improvement methods.

The port logistics service industry $[4,9,10]$ is a customer-oriented consumer market, and the ability to accurately determine customers' needs and quickly satisfy those needs is of immense assistance to companies' ability to expand their market share and boost profit. It is therefore very important for service providers $[9,10]$ to determine factors affecting service quality (the question of what), and, at the same time, when there is a gap between customers' perceived service quality performance and their expectations, it is also extremely important for companies to constantly propose solutions for raising service quality (the question of how).

Because there may be certain correlations or relationships [16] among criteria influencing service quality (the question of what), and also among solutions for boosting service quality (the question of how) (implying that these criteria are not necessarily mutually independent [17], but are instead interdependent and have a feedback relationship [1, 2, 9, 10]), assessment of the weights and performance values can be best performed employing the multiple criteria decision-making (MCDM) method [18-21]. This study consequently seeks to clarify the causal relationship between factors/solutions through an in-depth investigation and 
analysis of the causal relationship between the what and how questions, and then convert the causal relationship between factors/solutions into a clear structural model [22, 23].

The Battelle Memorial Institute of Geneva proposed the Decision Making Trial and Evaluation Laboratory (DEMATEL) technique [24-26] as a means of implementing scientific and human affairs programs between 1972 and 1976. The DEMATEL technique can be effectively used to confirm and help decision-makers to understand the complex causal relationships between various factors that exist in structural model concerning relevant research topics. This technique involves the use of matrices and relevant mathematical theory to calculate the causal relationships and the intensity of the influence between factors. Previous studies have shown that the DEMATEL technique can be applied to many management issues and problems [27], such as marketing and logistics management, service quality management, performance evaluation, supply chain management, and supplier selection, etc.

The effective evaluation of the weights of criteria (clusters) and sub-criteria (elements) is an important issue in MCDM problems [28]. In general, the evaluated criteria and subcriteria may be interdependent and have feedback relationships, in which case the decision structure cannot be built with a hierarchical structure, and a network structure is appropriate instead. The Analytic Network Process (ANP) technique [16] plays an important role in solving this type of MCDM problem, and is used to obtain the weights of all clusters and elements after considering the interdependence and feedback relationships among criteria, objectives, and elements.

This study therefore proposes the use of a hybrid multiple criteria decision-making model incorporating AHP, DEMATEL, and ANP to assess the degree of correlation between factors and solutions, the strength of their influence, and their relative level of importance. Nevertheless, in all types of enterprise diagnostics, it is necessary to ask what is the most important, why the problem occurred (the question of what) or how to resolve it (the question of how). This study tends to believe that the latter is more important. Because enterprises ultimately need solutions, the elimination of various factors that have a negative influence on enterprise performance can provide customers a greater degree of satisfaction. Based on this reasoning, this study focuses on port logistics center service quality solutions, and uses the hybrid MCDM model developed in this paper to illuminate the assessment process employed in this study.

This paper consists of four sections. Apart from the introduction in the current section, the second section introduces the research methods and theoretical basis used in this paper, and constructs a hybrid MCDM model, the third section uses a case study to explain the model's functioning. The final section presents discussions and conclusion.

\section{Methodology}

This section describes the construction of a hybrid MCDM model incorporating the AHP, DEMATEL, and ANP methods that can be applied effectively, and is scientific and systematic. The proposed hybrid MCDM method based on AHP, DEMATEL, and ANP concepts can be summarized as follows:

Step 1: Find related clusters and elements of the decision-making problem.

Step 2: Use the DEMATEL technique to construct a network framework.

Step 2.1: Calculate the initial direct-relation matrix.

Step 2.2: Calculate the normalized direct-relation matrix and derive the total direct/indirect matrix. 
Step 2.3: Set a threshold value and obtain the threshold total direct/indirect matrix.

Step 2.4: Find the normalized threshold total direct/indirect matrix.

Step 2.5: Find the influence coefficients of cluster $C_{i}$ on cluster $C_{j}$ and build the network framework.

Step 3: Use the AHP technique to find the influence priority vector of a given set of elements in a cluster on any element in the same cluster or a different cluster.

Step 3.1: Establish pair-wise comparison matrices for all clusters and all elements versus related clusters.

Step 3.2: Consistency testing.

Step 3.3: Calculate the weights of $n_{j}$ elements in cluster $C_{j}$.

Step 4: Build an unweighted supermatrix.

Step 5: Obtain a weighted supermatrix.

Step 6: Find the limiting supermatrix.

To be easy to understand the proposed model, the flow chart of the hybrid MCDM method in this article can be shown as Fig. 1.

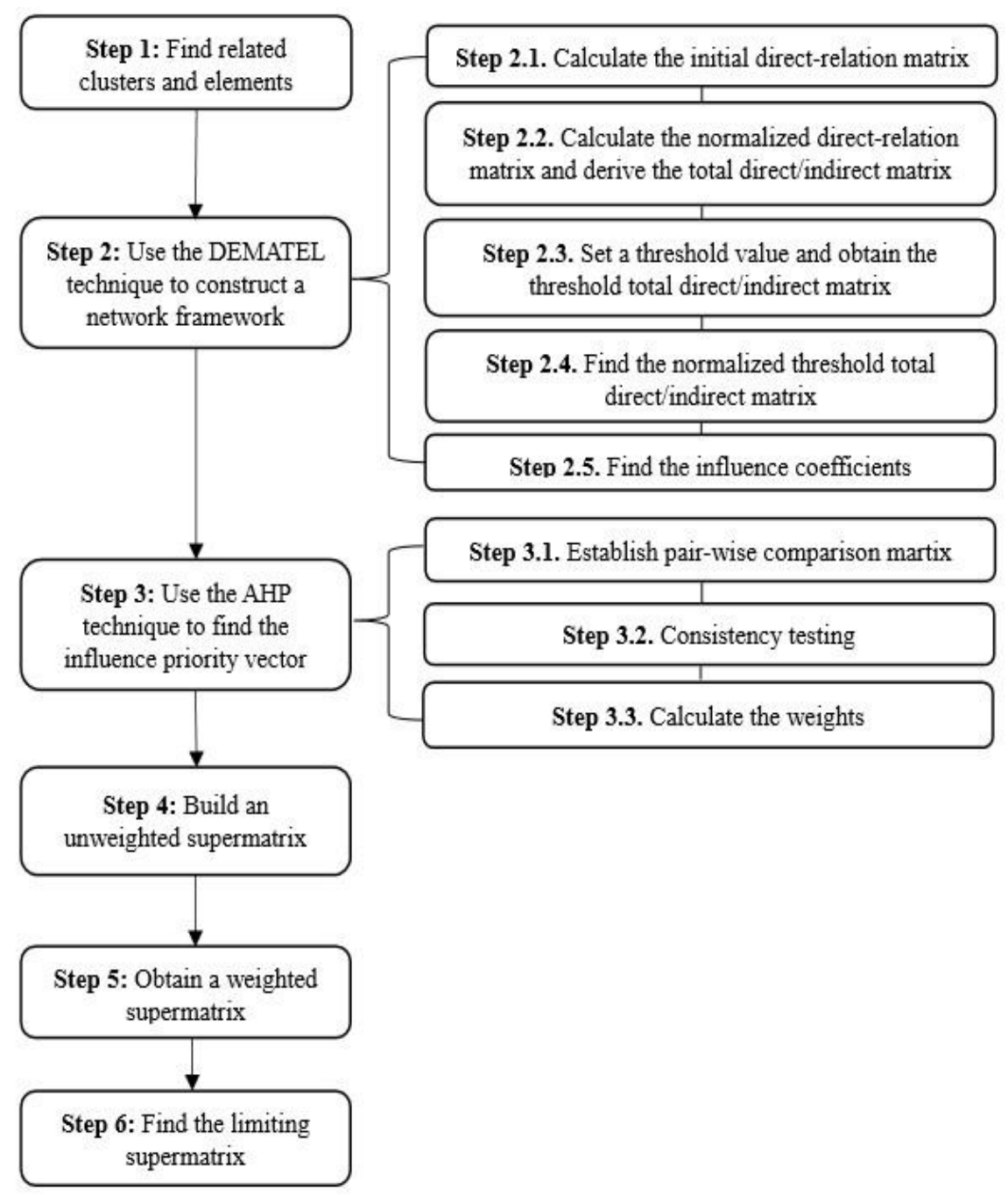

Fig. 1 flow chart of the hybrid MCDM method 


\subsection{Finding related clusters and elements in the decision problem}

Based on the research topic, we first located related clusters and the elements in those clusters that could be used to resolve the problem. The clusters and elements were obtained from the academic literature and from consultation with managers and experts concerning the research topic. Here we supposed that the network consists $n$ clusters (i.e., $\left.C_{1}, C_{2}, \ldots, C_{i}, \ldots, C_{n}\right)$ and $n_{i}$ elements $\left(i . e ., e_{i 1}, e_{i 2}, \ldots, e_{i n_{i}}\right)$ versus related cluster $C_{i}$.

\subsection{Use of the DEMATEL technique to construct the network framework}

The network framework can be constructed using the relationships and coefficients between clusters found by via the DEMATEL technique. The steps employed in the DEMATEL technique are explained as follows:

\subsubsection{Calculation of the initial direct-relation matrix}

Assume that $p$ experts (i.e., $E_{1}, E_{2}, \ldots, E_{p}$ ) are asked to indicate the degree of direct influence of each cluster $C_{i}$ on each cluster $C_{j}$. In this study, we employed a scale in which $0,1,2,3$, and 4 represented the range from 'no influence' to 'very high influence.'

Let $b_{i j}^{k}, k=1,2, \ldots, p, \forall i, j=1,2, \ldots, n$, be the degree to which $C_{i}$ affects $C_{j}$ given by respondent $E_{k}$. The separated initial direct-relation matrix $B^{k}$ given by expert $E_{k}$ is therefore

$$
B^{k}=\left(b_{i j}^{k}\right)_{n \times n},
$$

where $b_{i j}^{k}=0, \quad \forall i=j$.

The initial direct-relation matrix $B$ can then be constructed as follows:

$$
B=\left(b_{i j}\right)_{n \times n},
$$

where $b_{i j}=0, \forall i=j$; and $b_{i j}=\sum_{k=1}^{p} b_{i j}^{k} / p, \quad \forall i \neq j$.

2.2.2 Calculation of the normalized direct-relation matrix and derivation of the total direct/indirect matrix

Letting $\lambda=\max \left\{\max _{i}\left\{\sum_{j=1}^{n} b_{i j}\right\}, \max _{j}\left\{\sum_{i=1}^{n} b_{i j}\right\}\right\}$, the normalized direct-relation matrix $X$ can then be obtained:

$$
X=(1 / \lambda) \times B
$$

When $\lim _{t \rightarrow \infty} X^{t}=(0)_{n \times n}$, the total direct/indirect matrix $T$ can now be obtained.

$$
T=X(I-X)^{-1}
$$

2.2.3 Setting a threshold value and obtaining the threshold total direct/indirect matrix

In order to reduce the complexity of the causal relationships between clusters, decisionmakers can set a threshold value for the influence level. When an influence value in the total direct/indirect matrix $T$ is higher than the threshold value, it can be chosen and converted to a 
threshold total direct/indirect matrix. There are many methods that can be used to set the threshold value [29, 30]. In this paper, the scree test [31], derived by plotting the threshold values against the number of influences in their order of extraction, is used to determine the number of influences based on the threshold value considered. When a threshold value has been determined, the threshold total direct/indirect matrix can be identified.

Assume that total direct/indirect matrix $T=\left(t_{i j}\right)_{n \times n}$. Let $\beta$ be the threshold value. The threshold total direct/indirect matrix $T^{\beta}$ can now be obtained:

$$
T^{\beta}=\left(t_{i j}^{\beta}\right)_{n \times n}
$$

where $t_{i j}^{\beta}= \begin{cases}t_{i j}, & \text { if } t_{i j}>\beta \\ 0, & \text { if } t_{i j} \leq \beta\end{cases}$

\subsubsection{Finding the normalized threshold total direct/indirect matrix}

The normalized threshold total direct/indirect matrix $T^{N}$ can be obtained as follows:

$$
T^{N}=\left(t_{i j}^{N}\right)_{n \times n}
$$

where $t_{i j}^{N}=t_{i j}^{\beta} / S_{i}, \quad S_{i}=\sum_{j=1}^{n} t_{i j}^{\beta}$.

2.2.5 Finding the influence coefficients of cluster $C_{i}$ on cluster $C_{j}$ and building the network framework

The influence coefficients $f_{i j}$ of cluster $C_{i}$ on cluster $C_{j}$ can now be obtained based on the results shown in Section 2.2.4. That is, $f_{i j}=t_{i j}^{N}$.

This completes the construction of a network framework derived from the research topic on the basis of influencing relationships and the coefficients between clusters.

\subsection{Use of the AHP technique to find influence priority vectors}

The influences of a given set of elements in a cluster on any one element in the network can be determined using a priority vector derived from pair-wise comparison matrices using AHP technique. The steps employed in the AHP technique [1, 17] are summarized as follows:

2.3.1 Establishment of pair-wise comparison matrices for all clusters and all elements versus related clusters

In this study, the AHP questionnaires were designed based on the network framework. The linguistic values shown in Table 1 were used to evaluate the relative influence (importance) of a given set of elements in a cluster on any element in the same cluster or a different cluster.

Assume that there are $p$ experts (i.e., $\left.E_{1}, E_{2}, \ldots, E_{p}\right)$ in a committee. These experts are responsible for assessing the relative importance of a given $n_{j}$ elements (i.e., $\left.e_{j 1}, e_{j 2}, \ldots, e_{j n_{j}}\right)$ in cluster $C_{j}$ on any element in the same cluster or a different cluster using the basic scale shown in Table 1.

Letting $a_{t s}^{k}$ and $k=1,2, \ldots, p, \forall t, s=1,2, \ldots, n_{j}$ is the relative importance of element $e_{j t}$ to $e_{j s}$ in cluster $C_{j}$ given by expert $E_{k}$ after considering the influence on any element in 
the same cluster or a different cluster. The pair-wise comparison matrix $A^{k}$ of the relative importance of elements $e_{j t}$ and $e_{j s}$ given by expert $E_{k}$ can be constructed as follows:

$$
A^{k}=\left[a_{t s}^{k}\right]_{n_{j} \times n_{j}},
$$

where $a_{t s}^{k}=1, \forall t=s ;$ and $a_{t s}^{k}=1 / a_{s t}^{k}, \quad \forall t \neq s$.

Table 1 Basic scale used in the AHP technique

\begin{tabular}{|c|l|l|}
\hline $\begin{array}{c}\text { Intensity of } \\
\text { importance }\end{array}$ & \multicolumn{1}{|c|}{ Definition } & \multicolumn{1}{c|}{ Explanation } \\
\hline 1 & Equal importance & Two activities contribute equally to the objective \\
\hline 3 & $\begin{array}{l}\text { Weak importance of one } \\
\text { over another }\end{array}$ & Experience and judgment slightly favor one activity over another \\
\hline 5 & $\begin{array}{l}\text { Essential or strong } \\
\text { importance }\end{array}$ & Experience and judgment strongly favor one activity over another \\
\hline 7 & $\begin{array}{l}\text { Very strong or demonstrated } \\
\text { importance }\end{array}$ & $\begin{array}{l}\text { An activity is favored very strongly over another; its dominance } \\
\text { can be demonstrated in practice }\end{array}$ \\
\hline 9 & Absolute importance & $\begin{array}{l}\text { The evidence favoring one activity over another is of the highest } \\
\text { possible order of affirmation }\end{array}$ \\
\hline $2,4,6,8$ & $\begin{array}{l}\text { Intermediate values between } \\
\text { adjacent scale values }\end{array}$ & When compromise is needed \\
\hline
\end{tabular}

Source: [17]

\subsubsection{Consistency testing}

Consistency testing is an important element of the AHP technique [17], and can be performed using the consistency ratio (C.R.), which is defined as:

$$
\text { C.R. }=\frac{\text { C.I. }}{R . I .}
$$

where C.I. and R.I. denote the consistency index and random index. And

$$
\text { C.I. }=\frac{\lambda_{\max }^{k}-n_{j}}{n_{j}-1}
$$

where $n_{j}$ is the number of elements compared, and $\lambda_{\max }^{k}$ is the eigenvalue of the pair-wise comparison matrix $A^{k}=\left[a_{t s}^{k}\right]_{n_{j} \times n_{j}}$.

Here $\lambda_{\max }^{k}$ is calculated by the following steps:

(1) Calculate the weight $w_{t}^{k}$ of element $e_{j t}$.

$$
w_{t}^{k}=\left(\sum_{s=1}^{n_{j}}\left(a_{t s}^{k} / \sum_{t=1}^{n_{j}} a_{t s}^{k}\right)\right) / n_{j}, \quad t=1,2, \ldots, n_{j} ; k=1,2, \ldots, p .
$$

(2) Calculate the eigenvalue $\lambda_{\max }^{k}$ of pair-wise comparison matrix $A^{k}=\left[a_{t s}^{k}\right]_{n_{j} \times n_{j}}$.

$$
\lambda_{\text {max }}^{k}=\left(1 / n_{j}\right)\left(\sum_{t=1}^{n_{j}}\left(\sum_{s=1}^{n_{j}} a_{t s}^{k} w_{s}^{k} / w_{t}^{k}\right)\right)
$$


where $w_{s}^{k}$ is the weight of element $e_{j s}$.

The R.I. value can be obtained from Table 2. When the C.R. value is less than or equal to 0.1 , the consistency test is successful [17].

Table 2 Random index

\begin{tabular}{|c|c|c|c|c|c|c|c|}
\hline$n$ & 1 & 2 & 3 & 4 & 5 & 6 & 7 \\
\hline R.I. & 0.00 & 0.00 & 0.58 & 0.90 & 1.12 & 1.24 & 1.32 \\
\hline
\end{tabular}

Source: [17]

2.3.3 Calculate the weights of $n_{j}$ elements in cluster $C_{j}$

Let there be $q \leq p$ experts whose evaluation results pass the consistency test. Let $m_{t s}^{r}$, $r=1,2, \ldots, q, \forall t, s=1,2, \ldots, n_{j}$, be the relative importance of element $e_{j t}$ to $e_{j s}$ given by expert $E_{r}$. The pair-wise comparison matrix $M$ of the relative importance of all elements given by all $q$ experts can now be constructed as follows:

$$
M=\left[m_{t s}\right]_{n_{j} \times n_{j}},
$$

where $m_{t s}=\left(\prod_{r=1}^{q} m_{t s}^{r}\right)^{1 / q}$, if $t<s ; m_{t s}=1, \quad \forall t=s ;$ and $m_{s t}=1 / m_{t s}, \forall t \neq s$.

Let $w=\left(w_{1}, w_{2}, \ldots, w_{t}, \ldots, w_{n_{j}}\right)$ be the eigenvecter of the pair-wise comparison matrix $M=\left[m_{t s}\right]_{n_{j} \times n_{j}}$. The influence weight $w_{t}$ of element $e_{j t}$ can now be obtained by

$$
w_{t}=\left(\sum_{s=1}^{n_{j}}\left(m_{t s} / \sum_{t=1}^{n_{j}} m_{t s}\right)\right) / n_{j}, \quad t=1,2, \ldots, n_{j} .
$$

\subsection{Building an unweighted supermatrix}

The general form of an unweighted supermatrix can be represented as follows:

$$
W=\left(W_{i j}\right)_{n \times n},
$$

where $W_{i j}$ is called a "block" of the unweighted supermatrix, and is a matrix of the form:

$$
W_{i j}=\left(w_{u v}^{i j}\right)_{n_{i} \times n_{j}}, i, j=1,2, \ldots, n ; u=1,2, \ldots, n_{i} ; v=1,2, \ldots, n_{j} .
$$

The $f^{\text {th }}$ column $\left(w_{1 f}^{i j} w_{2 f}^{i j} \cdots w_{t f}^{i j} \cdots w_{n_{i} f}^{i j}\right)^{T}$ of $W_{i j}$ is the eigenvector of the influence (importance) of $n_{i}$ elements $\left(e_{i 1}, e_{i 2}, \ldots, e_{i n_{i}}\right)$ in cluster $C_{i}$ on the $f^{\text {th }}$ element $e_{i f}$ in cluster $C_{j}$. If the $i^{\text {th }}$ cluster has no influence on the $j^{\text {th }}$ cluster, then set $W_{i j}=(0)_{n_{i} \times n_{j}}$.

2.5 Obtaining the weighted supermatrix

The weighted supermatrix $W^{w}$ can be calculated:

$$
W^{w}=\left(W_{i j}^{w}\right)_{n \times n},
$$

where 


$$
W_{i j}^{w}=\left(f_{j i} \times w_{u v}^{i j}\right)_{n_{i} \times n_{j}}, i, j=1,2, \ldots, n ; u=1,2, \ldots, n_{i} ; \quad v=1,2, \ldots, n_{j} ;
$$

and $f_{j i}$ is the influence coefficient of cluster $C_{j}$ on cluster $C_{i}$.

\subsection{Finding the limiting supermatrix}

The weighted supermatrix can be stabilized by multiplying the weighted supermatrix by itself until the values of rows in the supermatrix converge on the same value for each column of the supermatrix. The resulting stabilized supermatrix is the limiting supermatrix. The priority of all elements can be determined based on the limiting supermatrix.

\section{Application of the hybrid MCDM model: An illustrative example}

This section uses the hybrid MCDM model constructed in this paper to assess the degree of correlation between port logistics center service quality solutions, the strength of their influence, and their relative level of importance. This section employs a hypothetical case as an example to examine this paper's hybrid MCDM model, and includes a description of the problem and the various analytical procedures involved.

Step 1: Identify related clusters and elements

In order to assess whether the quality of its services was sufficient to meet customers' true needs, a logistics center at Kaohsiung port in Taiwan sought to locate factors affecting the logistics center's service quality. The results of this assessment ultimately revealed that the quality of some services did not meet requirements. In order to convert customer service needs to concrete, feasible solutions for improving service quality, the Kaohsiung port logistics center operator performed analysis focusing on the three major aspects of convenience, professionalism, and service personnel, and drafted nine concrete, feasible solutions [9, 10, 32-38] with the content shown in Table 3. In addition, to ensure that subsequent analysis could be clearly expressed, these three major aspects were represented as three clusters, and the nine feasible solutions represented as nine elements.

Table 3 List of solutions influencing service quality for Kaohsiung port logistics center

\begin{tabular}{|l|l|l|}
\hline \multicolumn{1}{|c|}{ Aspects } & \multicolumn{1}{|c|}{ Solutions } & \multicolumn{1}{c|}{ Descriptions } \\
\hline $\begin{array}{l}\text { Convenience } \\
\left(C_{1}\right)\end{array}$ & $\begin{array}{l}\text { Comprehensive information } \\
\text { system }\left(e_{11}\right)\end{array}$ & $\begin{array}{l}\text { Has a 24-hour query system, provides answers to customer } \\
\text { queries concerning cargo status at any time. }\end{array}$ \\
\cline { 2 - 3 } & Single-window service $\left(e_{12}\right)$ & $\begin{array}{l}\text { Single-window service, ensures that customers can obtain all } \\
\text { services provided by the logistics center at a single counter. }\end{array}$ \\
\cline { 2 - 3 } & $\begin{array}{l}\text { Simplified administrative } \\
\text { operating procedures }\left(e_{13}\right)\end{array}$ & $\begin{array}{l}\text { Simplification of logistics center's internal administrative } \\
\text { procedures, accelerating implementation of operating } \\
\text { procedures and reduction of customer waiting time. }\end{array}$ \\
\hline \multirow{2}{*}{$\begin{array}{l}\text { Service personnel } \\
\left(C_{2}\right)\end{array}$} & Service attitude $\left(e_{21}\right)$ & $\begin{array}{l}\text { The improvement of service attitude among personnel will } \\
\text { enhance customers' satisfaction with service quality. }\end{array}$ \\
\cline { 2 - 3 } & Professional skills $\left(e_{22}\right)$ & $\begin{array}{l}\text { Enhancement of the professional skills of service personnel } \\
\text { will enhance customers' satisfaction with service quality. }\end{array}$ \\
\cline { 2 - 3 } & Responsiveness $\left(e_{23}\right)$ & $\begin{array}{l}\text { Enhancement of the responsiveness of service personnel will } \\
\text { enhance customers' satisfaction with service quality. }\end{array}$ \\
\hline
\end{tabular}


Table 3 List of solutions influencing service quality for Kaohsiung port logistics center (Continued)

\begin{tabular}{|l|l|l|}
\hline \multicolumn{1}{|c|}{ Aspects } & \multicolumn{1}{|c|}{ Solutions } & \multicolumn{1}{c|}{ Descriptions } \\
\hline $\begin{array}{l}\text { Professionalism } \\
\left(C_{3}\right)\end{array}$ & $\begin{array}{l}\text { Enhanced warehouse safety } \\
\text { management }\left(e_{31}\right)\end{array}$ & $\begin{array}{l}\text { The logistics center bears responsibility for safety of cargo } \\
\text { while in warehouse and consequently provides enhanced } \\
\text { safety management, reducing theft, damage, and missing } \\
\text { goods, and boosting the logistics center's service quality. }\end{array}$ \\
\cline { 2 - 3 } & $\begin{array}{l}\text { Safety of cargo during } \\
\text { transport }\left(e_{32}\right)\end{array}$ & $\begin{array}{l}\text { The logistics center bears responsibility for maintaining } \\
\text { cargo safety during transport. }\end{array}$ \\
\cline { 2 - 3 } & $\begin{array}{l}\text { Cargo tracking and } \\
\text { management ability }\left(e_{33}\right)\end{array}$ & $\begin{array}{l}\text { The logistics center must be able to know the status of cargo } \\
\text { at all times while in warehouse and during transport. }\end{array}$ \\
\hline
\end{tabular}

Note: The code names of each aspect and solution are shown in parentheses.

\section{Step 2: Use of the DEMATEL technique to construct a network framework}

Step 2.1. Five experts (three senior managers of international logistics companies with at least 20 years working experience, and two professors of international logistics field with 15 years teaching and practical experience) were asked to indicate the degree of direct influence of each cluster $C_{i}$ on each cluster $C_{j}$. The values $0,1,2,3$, and 4 employed in the scale in this example represent the range from 'no influence' to 'very high influence.'

Using equation (1), the separated initial direct-relation matrices given by the five experts were as follows:

$$
B^{1}=\left(\begin{array}{lll}
0 & 4 & 3 \\
3 & 0 & 2 \\
4 & 3 & 0
\end{array}\right), B^{2}=\left(\begin{array}{lll}
0 & 4 & 2 \\
1 & 0 & 3 \\
2 & 4 & 0
\end{array}\right), B^{3}=\left(\begin{array}{lll}
0 & 4 & 2 \\
2 & 0 & 3 \\
2 & 4 & 0
\end{array}\right), B^{4}=\left(\begin{array}{lll}
0 & 3 & 2 \\
3 & 0 & 3 \\
4 & 4 & 0
\end{array}\right), B^{5}=\left(\begin{array}{lll}
0 & 3 & 3 \\
3 & 0 & 4 \\
4 & 4 & 0
\end{array}\right) .
$$

Using equation (2), the initial direct-relation matrix $B$ was be constructed as

$$
B=\left(\begin{array}{ccc}
0 & 3.6 & 2.4 \\
2.4 & 0 & 3.0 \\
3.2 & 3.8 & 0
\end{array}\right)
$$

Step 2.2. We took $\lambda=\max \{6,5.4,7,5.6,7.4,5.4\}=7.4$. The normalized direct-relation matrix $X$ could then be obtained using equation (3):

$$
X=(1 / 7.4) \times\left(\begin{array}{ccc}
0 & 3.6 & 2.4 \\
2.4 & 0 & 3.0 \\
3.2 & 3.8 & 0
\end{array}\right)=\left(\begin{array}{ccc}
0 & 0.486 & 0.324 \\
0.324 & 0 & 0.405 \\
0.432 & 0.514 & 0
\end{array}\right)
$$

Using equation (4), the total direct/indirect matrix $T$ was

$$
T=X(I-X)^{-1}=\left(\begin{array}{ccc}
0 & 0.486 & 0.324 \\
0.324 & 0 & 0.405 \\
0.432 & 0.514 & 0
\end{array}\right) \times\left(\begin{array}{ccc}
2.228 & 1.836 & 1.465 \\
1.404 & 2.420 & 1.435 \\
1.684 & 2.037 & 2.371
\end{array}\right)=\left(\begin{array}{ccc}
1.228 & 1.836 & 1.465 \\
1.404 & 1.420 & 1.435 \\
1.684 & 2.037 & 1.371
\end{array}\right) \text {. }
$$

Step 2.3. According to the scree test [31], the relationships between threshold value and the number of influence in matrix $T$ are depicted as Table 4, taking 1.41 as the threshold value is obviously appropriate. That is, the threshold value $\beta=1.41$. 
Table 4 The relationships between threshold value and number of influence

\begin{tabular}{|c|c|c|c|c|c|c|}
\hline Threshold value & 1.21 & 1.31 & 1.41 & 1.51 & 1.61 & 1.71 \\
\hline Number of influence & 9 & 9 & 6 & 3 & 3 & 2 \\
\hline
\end{tabular}

Then, by using equation (5), the threshold total direct/indirect matrix $T^{\beta}$ was derived as:

$$
T^{\beta}=\left(\begin{array}{ccc}
0 & 1.836 & 1.465 \\
0 & 1.420 & 1.435 \\
1.684 & 2.037 & 0
\end{array}\right)
$$

Step 2.4. In the threshold total direct/indirect matrix shown above, the three row sums are:

$$
\begin{aligned}
& S_{1}=0+1.836+1.465=3.301, \\
& S_{2}=0+1.420+1.435=2.855, \\
& S_{3}=1.684+2.037=3.721 .
\end{aligned}
$$

Furthermore, using equation (6), the normalized threshold total direct/indirect matrix $T^{N}$ was obtained as

$$
T^{N}=\left(\begin{array}{ccc}
0 & 0.556 & 0.444 \\
0 & 0.497 & 0.503 \\
0.453 & 0.547 & 0
\end{array}\right)
$$

Step 2.5. Based on the normalized threshold total direct/indirect matrix $T^{N}$, the influence coefficients $f_{i j}$ of cluster $C_{i}$ on cluster $C_{j}$ were obtained as:

$$
\begin{array}{lll}
f_{11}=0, & f_{12}=0.556, & f_{13}=0.444 ; \\
f_{21}=0, & f_{22}=0.497 & f_{23}=0.503 ; \\
f_{31}=0.453, & f_{32}=0.547, & f_{33}=0 .
\end{array}
$$

Step 3: Use of the AHP technique to evaluate relative importance

Step 3.1. Three experts (two senior managers of international logistics companies with at least 20 years working experience, and one professor of international logistics field with 15 years teaching and practical experience) were asked to evaluate the relative importance (influence) of 'service attitude $\left(e_{21}\right)$,' 'professional skills $\left(e_{22}\right)$,' and 'responsiveness $\left(e_{23}\right)$,' in cluster $C_{2}$ on element 'comprehensive information system $\left(e_{11}\right)$,' in cluster $C_{1}$. Then, by equation (7), the three pair-wise comparison matrices $\left(A^{1}, A^{2}, A^{3}\right)$ based on the evaluation results were obtained as

$$
A^{1}=\left(\begin{array}{ccc}
1 & 1 / 5 & 1 / 3 \\
5 & 1 & 2 \\
3 & 1 / 2 & 1
\end{array}\right), A^{2}=\left(\begin{array}{ccc}
1 & 1 / 7 & 1 / 2 \\
7 & 1 & 3 \\
2 & 1 / 3 & 1
\end{array}\right), A^{3}=\left(\begin{array}{ccc}
1 & 1 / 8 & 1 / 3 \\
8 & 1 & 2 \\
3 & 1 / 2 & 1
\end{array}\right) .
$$

Step 3.2. By using equation (10), the importance weights $w_{t}^{k}(k=1,2,3 ; t=1,2,3)$ of elements $e_{2 t}(t=1,2,3)$ relative to element $e_{11}$ were: 


$$
\begin{aligned}
& w_{1}^{1}=0.110, w_{2}^{1}=0.581, w_{3}^{1}=0.309 ; \\
& w_{1}^{2}=0.103, w_{2}^{2}=0.681, w_{3}^{2}=0.216 ; \\
& w_{1}^{3}=0.087, w_{2}^{3}=0.627, w_{3}^{3}=0.286 .
\end{aligned}
$$

Using equation (11), the eigenvalues $\lambda_{\max }^{k}(k=1,2,3)$ of pair-wise comparison matrices $A^{k}(k=1,2,3)$ were:

$$
\lambda_{\max }^{1}=3, \quad \lambda_{\max }^{2}=3.002, \quad \lambda_{\max }^{3}=3.011 .
$$

Thus, by using equations (8) and (9), the consistency indices and consistency ratios of the pair-wise comparison matrices $A^{k}(k=1,2,3)$ were:

$$
\begin{array}{ll}
\text { C.I. }=\frac{\lambda_{\max }^{1}-n_{1}}{n_{1}-1}=\frac{3.000-3.000}{2}=0, & C . R .=\frac{C . I .}{R . I .}=\frac{0}{0.58}=0<0.1 ; \\
\text { C.I. }=\frac{\lambda_{\max }^{2}-n_{2}}{n_{2}-1}=\frac{3.002-3.000}{2}=0.001, & C . R .=\frac{C . I .}{R . I .}=\frac{0.001}{0.58}=0.002<0.1 ; \\
\text { C.I. }=\frac{\lambda_{\max }^{3}-n_{3}}{n_{3}-1}=\frac{3.011-3.000}{2}=0.006, & \text { C.R. }=\frac{C . I .}{R . I .}=\frac{0.006}{0.58}=0.010<0.1 ;
\end{array}
$$

According to the consistency test results shown above, the consistency test was successful.

Step 3.3. Thus, using equation (12), the pair-wise comparison matrix $M$ of the relative importance of all elements given by three experts could be constructed as:

$$
M=\left(\begin{array}{ccc}
1 & 0.153 & 0.381 \\
6.542 & 1 & 2.289 \\
2.621 & 0.437 & 1
\end{array}\right)
$$

By using equation (13), the influence weights $w_{t}(t=1,2,3)$ of elements $e_{2 t}(t=1,2,3)$ relative to element $e_{11}$ were

$$
w_{1}=0.100, w_{2}=0.632, w_{3}=0.268
$$

By using similar procedures, the relative importance (influence) of a given set of elements in a cluster on any element in the same cluster or a different cluster could be found.

Step 4: Construction of an unweighted supermatrix

In accordance with Step 3, the first column of block $W_{21}$ of the unweighted supermatrix was $\left(\begin{array}{lll}0.100 & 0.632 & 0.268\end{array}\right)^{T}$.

By using equation (15), and employing similar procedures, all blocks could be obtained:

$$
W_{11}=(0)_{3 \times 3}, \quad W_{12}=(0)_{3 \times 3}, \quad W_{33}=(0)_{3 \times 3} \text {, }
$$




$$
\begin{aligned}
& W_{13}=\left(\begin{array}{lll}
0.486 & 0.436 & 0.410 \\
0.213 & 0.252 & 0.306 \\
0.301 & 0.312 & 0.284
\end{array}\right), \quad W_{21}=\left(\begin{array}{lll}
0.100 & 0.286 & 0.196 \\
0.632 & 0.458 & 0.502 \\
0.268 & 0.256 & 0.302
\end{array}\right), \quad W_{22}=\left(\begin{array}{lll}
0.202 & 0.296 & 0.319 \\
0.452 & 0.408 & 0.396 \\
0.346 & 0.2960 .285
\end{array}\right), \\
& W_{23}=\left(\begin{array}{lll}
0.203 & 0.214 & 0.266 \\
0.485 & 0.451 & 0.488 \\
0.312 & 0.335 & 0.246
\end{array}\right), \quad W_{31}=\left(\begin{array}{lll}
0.340 & 0.378 & 0.254 \\
0.258 & 0.187 & 0.320 \\
0.402 & 0.435 & 0.426
\end{array}\right), \quad W_{32}=\left(\begin{array}{lll}
0.338 & 0.301 & 0.330 \\
0.284 & 0.271 & 0.268 \\
0.378 & 0.428 & 0.402
\end{array}\right) \text {. }
\end{aligned}
$$

Using equation (14), the unweighted supermatrix could be represented as:

$$
W=\left(\begin{array}{ccccccccc}
0 & 0 & 0 & 0 & 0 & 0 & 0.486 & 0.436 & 0.410 \\
0 & 0 & 0 & 0 & 0 & 0 & 0.213 & 0.252 & 0.306 \\
0 & 0 & 0 & 0 & 0 & 0 & 0.301 & 0.312 & 0.284 \\
0.100 & 0.286 & 0.196 & 0.202 & 0.296 & 0.319 & 0.203 & 0.214 & 0.266 \\
0.632 & 0.458 & 0.502 & 0.452 & 0.408 & 0.396 & 0.485 & 0.451 & 0.488 \\
0.268 & 0.256 & 0.302 & 0.346 & 0.296 & 0.285 & 0.312 & 0.335 & 0.246 \\
0.340 & 0.378 & 0.254 & 0.338 & 0.301 & 0.330 & 0 & 0 & 0 \\
0.258 & 0.187 & 0.320 & 0.284 & 0.271 & 0.268 & 0 & 0 & 0 \\
0.402 & 0.435 & 0.426 & 0.378 & 0.428 & 0.402 & 0 & 0 & 0
\end{array}\right) .
$$

Step 5: Calculation of the weighted supermatrix

Using equation (17), all weighted blocks were:

$$
\begin{aligned}
& W_{11}^{w}=(0)_{3 \times 3}, \quad W_{12}^{w}=(0)_{3 \times 3}, \quad W_{33}^{w}=(0)_{3 \times 3}, \\
& W_{13}^{w}=f_{31} \times W_{13}=0.453 \times\left(\begin{array}{lll}
0.486 & 0.436 & 0.410 \\
0.213 & 0.252 & 0.306 \\
0.301 & 0.312 & 0.284
\end{array}\right)=\left(\begin{array}{lll}
0.220 & 0.198 & 0.186 \\
0.097 & 0.114 & 0.138 \\
0.136 & 0.141 & 0.129
\end{array}\right), \\
& W_{21}^{w}=f_{12} \times W_{21}=0.556 \times\left(\begin{array}{lll}
0.100 & 0.286 & 0.196 \\
0.632 & 0.458 & 0.502 \\
0.268 & 0.256 & 0.302
\end{array}\right)=\left(\begin{array}{lll}
0.056 & 0.159 & 0.109 \\
0.351 & 0.255 & 0.279 \\
0.149 & 0.142 & 0.168
\end{array}\right), \\
& W_{22}^{w}=f_{22} \times W_{22}=0.497 \times\left(\begin{array}{lll}
0.202 & 0.296 & 0.319 \\
0.452 & 0.408 & 0.396 \\
0.346 & 0.296 & 0.285
\end{array}\right)=\left(\begin{array}{lll}
0.100 & 0.147 & 0.158 \\
0.225 & 0.203 & 0.197 \\
0.172 & 0.147 & 0.142
\end{array}\right), \\
& W_{23}^{w}=f_{32} \times W_{23}=0.547 \times\left(\begin{array}{lll}
0.203 & 0.214 & 0.266 \\
0.485 & 0.451 & 0.488 \\
0.312 & 0.335 & 0.246
\end{array}\right)=\left(\begin{array}{lll}
0.111 & 0.117 & 0.145 \\
0.265 & 0.247 & 0.267 \\
0.171 & 0.183 & 0.135
\end{array}\right), \\
& W_{31}^{w}=f_{13} \times W_{31}=0.444 \times\left(\begin{array}{lll}
0.340 & 0.378 & 0.254 \\
0.258 & 0.187 & 0.320 \\
0.402 & 0.435 & 0.426
\end{array}\right)=\left(\begin{array}{lll}
0.151 & 0.168 & 0.113 \\
0.115 & 0.083 & 0.142 \\
0.178 & 0.193 & 0.180
\end{array}\right), \text { and }
\end{aligned}
$$




$$
W_{32}^{w}=f_{23} \times W_{32}=0.503 \times\left(\begin{array}{lll}
0.338 & 0.301 & 0.330 \\
0.284 & 0.271 & 0.268 \\
0.378 & 0.428 & 0.402
\end{array}\right)=\left(\begin{array}{lll}
0.170 & 0.152 & 0.166 \\
0.143 & 0.136 & 0.135 \\
0.190 & 0.215 & 0.202
\end{array}\right) \text {. }
$$

Using equation (16), the weighted supermatrix could then be represented as follows:

$$
W^{w}=\left(\begin{array}{ccccccccc}
0 & 0 & 0 & 0 & 0 & 0 & 0.220 & 0.198 & 0.186 \\
0 & 0 & 0 & 0 & 0 & 0 & 0.097 & 0.114 & 0.138 \\
0 & 0 & 0 & 0 & 0 & 0 & 0.136 & 0.141 & 0.129 \\
0.056 & 0.159 & 0.109 & 0.100 & 0.147 & 0.158 & 0.111 & 0.117 & 0.145 \\
0.351 & 0.255 & 0.279 & 0.225 & 0.203 & 0.197 & 0.265 & 0.247 & 0.267 \\
0.149 & 0.142 & 0.168 & 0.172 & 0.147 & 0.142 & 0.171 & 0.183 & 0.135 \\
0.151 & 0.168 & 0.113 & 0.170 & 0.152 & 0.166 & 0 & 0 & 0 \\
0.115 & 0.083 & 0.142 & 0.143 & 0.136 & 0.135 & 0 & 0 & 0 \\
0.178 & 0.193 & 0.189 & 0.190 & 0.215 & 0.202 & 0 & 0 & 0
\end{array}\right)
$$

Step 6: Obtaining the limiting supermatrix

Lastly, the limiting supermatrix could be represented as follows:

$$
W^{L}=\left(\begin{array}{lllllllll}
0.066 & 0.066 & 0.066 & 0.066 & 0.066 & 0.066 & 0.066 & 0.066 & 0.066 \\
0.039 & 0.039 & 0.039 & 0.039 & 0.039 & 0.039 & 0.039 & 0.039 & 0.039 \\
0.044 & 0.044 & 0.044 & 0.044 & 0.044 & 0.044 & 0.044 & 0.044 & 0.044 \\
0.129 & 0.129 & 0.129 & 0.129 & 0.129 & 0.129 & 0.129 & 0.129 & 0.129 \\
0.239 & 0.239 & 0.239 & 0.239 & 0.239 & 0.239 & 0.239 & 0.239 & 0.239 \\
0.154 & 0.154 & 0.154 & 0.154 & 0.154 & 0.154 & 0.154 & 0.154 & 0.154 \\
0.105 & 0.105 & 0.105 & 0.105 & 0.105 & 0.105 & 0.105 & 0.105 & 0.105 \\
0.089 & 0.089 & 0.089 & 0.089 & 0.089 & 0.089 & 0.089 & 0.089 & 0.089 \\
0.135 & 0.135 & 0.135 & 0.135 & 0.135 & 0.135 & 0.135 & 0.135 & 0.135
\end{array}\right)
$$

According to the limiting supermatrix, the weights of all elements were found to be as shown in Table 5.

Table 5 Weights of all elements

\begin{tabular}{|c|c|c|c|c|c|c|c|c|c|}
\hline Elements $\left(e_{i j}\right)$ & $e_{11}$ & $e_{12}$ & $e_{13}$ & $e_{21}$ & $e_{22}$ & $e_{23}$ & $e_{31}$ & $e_{32}$ & $e_{33}$ \\
\hline Weights $\left(w_{i j}\right)$ & 0.066 & 0.039 & 0.044 & 0.129 & 0.239 & 0.154 & 0.105 & 0.089 & 0.135 \\
\hline Ranking & 7 & 9 & 8 & 4 & 1 & 2 & 5 & 6 & 3 \\
\hline
\end{tabular}

According to Table 5, the three most important service quality solutions for this logistics center at Kaohsiung port are therefore 'professional skills $\left(e_{22}\right)$,' 'responsiveness $\left(e_{23}\right)$,' and 'cargo tracking and management ability $\left(e_{33}\right)$.' Furthermore, based on the weight distribution, the importance weights of the three aspects - convenience, service personnel, and professionalism - are $0.149,0.522$, and 0.329. Hence, 'service personnel,' which is ranked $1^{\text {st }}$, is the most important cluster influencing service quality at this logistics center, followed by 'professionalism' in second place, and 'convenience' is ranked last. 
Use of a hybrid MCDM method to evaluate key solutions influencing service quality at a port logistics center in Taiwan
Jiun-Yan Tsai, Ji-Feng Ding, Gin-Shuh Liang, Kung-Don Ye

\section{Discussion and conclusions}

Many papers in the literature investigate factors affecting service quality at international port logistics centers and solutions for the improvement of service quality, and both are important issues in the assessment of service quality at port logistics centers. Nevertheless, in assessing factors affecting service quality and assessing solutions for the improvement of service quality, each these influencing factors/solutions can be seen as sets of variables containing several criteria. The DEMATEL technique can be used in conjunction with an expert survey to clarify the causal relationships between individual criterion variables, and can both transform the causal relationships between individual criterion variables into a clear structural model [22], and also account for the interdependence among the criterion variables [23]. It is clear that the conventional AHP technique [17] cannot effectively handle situations in which criteria or sub-criteria have dependent relationships or feedback effects, which is because the AHP technique can only deal with criteria that are mutually independent. For its part, the ANP technique proposed by Saaty [16] is able to adequately deal with criteria that have dependent relationships or feedback effects, which is because ANP consists of AHP plus a feedback mechanism and uses a supermatrix to derive the degree of influence of mutual interdependence. As a consequence, this paper proposes the use of a hybrid MCDM model incorporating AHP, DEMATEL, and ANP to assess the causal relationships between criterion variables, including dependent relationships and feedback mechanisms. Lastly, this study focuses port logistics center service quality solutions, and applies the hybrid MCDM model constructed in this paper in order to explain its functioning and assessment procedures.

First, this paper constructs a hybrid MCDM model incorporating AHP, DEMATEL, and ANP. To ensure that this model was easy to apply, scientific, and systematic, a detailed explanation of application procedures is provided for each of the six operating steps. Second, using a hypothetical port logistics center case as an example, this paper applies the model to the assessment of port logistics center service quality solutions. Finally, via the various operating steps, the key logistics center service quality solutions are ranked, allowing logistics center operators to implement them in the resulting order of priority.

The advantages of the hybrid MCDM model combining the AHP, DEMATEL, and ANP methods can be summarized as follows:

(1) The ANP technique can be used to deal with feedback and dependence among evaluation criteria (including both clusters and elements within clusters).

(2) The DEMATEL technique can be used to gauge the degree of mutual dependence between clusters.

(3) The model ensures that the decision-making process is relatively realistic and effective.

Although the proposed hybrid MCDM model was used in this study to identify the weights of solutions relative to service quality at a port logistics center, it can also be applied to other evaluation/selection problems, such as the evaluation of risk factors, supplier selection, shipping alliance evaluation, port competitiveness evaluation, and many related management decision-making or strategy evaluation/selection problems. Furthermore, in practical assessment work, because the selection of solutions and selection of attributes or criteria tend to be vague and qualitative in nature, and it can be difficult to express assessment results as precise values, this assessment model can also be combined with fuzzy set theory [39] and linguistic variables [40] in order to deal with imprecise decision-making problems. 
Jiun-Yan Tsai, Ji-Feng Ding,

Gin-Shuh Liang, Kung-Don Ye
Use of a hybrid MCDM method to evaluate key solutions influencing service quality at a port logistics center in Taiwan

\section{REFERENCES}

[1] Liao, M. S., Ding, J. F., Liang, G. S. and Lee, K. L.: Key criteria for evaluating the green performance of ports. Journal of Testing and Evaluation, 44(4), 1791-1801, 2016. https://doi.org/10.1520/JTE20140354.

[2] Yang, Y. L., Ding, J. F., Chiu, C. C., Shyu, W. H., Tseng, W. J. and Chou, M. T.: Core risk factors influencing safe handling operations for container terminals at Kaohsiung port. Proceedings of the Institution of Mechanical Engineers, Part M, Journal of Engineering for the Maritime Environment, 230(2), 444-453, 2016.

[3] Ding, J. F.: Evaluating customer value for liner shipping companies in Taiwan: An empirical study. International Journal of Innovative Computing, Information \& Control (IJICIC), 5(7), 2031-2042, 2009.

[4] Yang, W. S., Liang, G. S. and Ding, J. F.: Identifying solutions for adding service value to international port logistics centers in Taiwan. Maritime Economics \& Logistics, 15(4), 395-415, 2013. https://doi.org/10.1057/mel.2013.15.

[5] Carbone, V. and Martino, M. De.: The changing role of ports in supply-chain management: an empirical analysis. Maritime Policy \& Management, 30(4), 305-320, 2003.

https://doi.org/10.1080/0308883032000145618.

[6] Robinson, D.: Boosting the capacity. Cargo Systems, 27(12), 25-27, 2000.

[7] Ding, J. F. and Tseng, W. J.: Fuzzy risk assessment on safety operations for exclusive container terminals at Kaohsiung port in Taiwan. Proceedings of the Institution of Mechanical Engineers, Part M, Journal of Engineering for the Maritime Environment, 227(2), 208-220, 2013.

[8] Ding, J. F., Chou, M. T., Yeh, I. C., Yang, Y. L., Chou, C. C. and Shyu, W. H.: An evaluation of key service effectiveness of Keelung port. Journal of Marine Science and Technology, 24(2), 174-183, 2016.

[9] Liang, G. S., Ding, J. F. and Pan, C. L.: Applying fuzzy quality function deployment to evaluate solutions of the service quality for international port logistics centres in Taiwan. Proceedings of the Institution of Mechanical Engineers, Part M: Journal of Eng. for the Maritime Environment, 226(4), 387-396, 2012.

[10] Ding, J. F.: Applying fuzzy quality function deployment (QFD) to identify solutions of service delivery system for port of Kaohsiung. Quality \& Quantity, 43(4), 553-570, 2009. https://doi.org/10.1007/s11135007-9138-7.

[11] Liang, G. S., Ding, J. F. and Kao, J. D.: The relationships between distribution centers' service delivery system and operating performance. Journal of Maritime Sciences, 17, 17-32, 2008.

[12] Lu, C. S.: An evaluation of logistics services requirements of international distribution centers in Taiwan. Transportation Journal, 43(4), 53-66, 2004.

[13] Huang, S. H. and Hsu, W. K.: An assessment of service quality for international distribution centers in Taiwan: A QFD approach with fuzzy AHP. Maritime Policy \& Management, 43(4), 509-523, 2016. https://doi.org/10.1080/03088839.2015.1134829.

[14] Parasuraman, A., Zethaml, V. A. and Berry, L. L.: A conceptual model of service quality and its implications for future research. Journal of Marketing, 49(4), 41-50, 1985. https://doi.org/10.2307/1251430.

[15] Parasuraman, A., Zethaml, V. A. and Berry, L. L.: SERVQUAL: A multiple-item scale for measuring consumer perceptions of service quality. Journal of Retailing, 64(1), 12-40, 1988.

[16] Saaty, T. L.: Decision Making with Dependence and Feedback: The Analytic Network Process. Pennsylvania: RWS Publications, 1996.

[17] Saaty, T. L.: The Analytic Hierarchy Process. New York: McGraw-Hill, 1980.

[18] Baykasoğlu, A., Kaplanoğlu, V., Durmuşoğlu, Z. D. U. and Şahin, C.: Integrating fuzzy DEMATEL and fuzzy hierarchical TOPSIS methods for truck selection. Expert Systems with Applications, 40(3), 899907, 2013. https://doi.org/10.1016/j.eswa.2012.05.046.

[19] Chang, B., Chang, C. W. and Wu, C.H.: Fuzzy DEMATEL method for developing supplier selection criteria. Expert Systems with Applications, 38(3), 1850-1858, 2011.

https://doi.org/10.1016/j.eswa.2010.07.114.

[20] Dalalah, D., Hayajneh, M. and Batieha, F.: A fuzzy multi-criteria decision making model for supplier selection. Expert Systems with Applications, 38(7), 8384-8391, 2011. https://doi.org/10.1016/j.eswa.2011.01.031.

[21] Hsu, C. Y., Chen, K. T. and Tzeng, G. H.: FMCDM with fuzzy DEMATEL approach for customers' choice behavior model. International Journal of Fuzzy Systems, 9(4), 236-246, 2007. 
[22] Hori, S. and Shimizu, Y.: Designing methods of human interface for supervisory control systems. Control Engineering Practice, 7(11), 1413-1419, 1999. https://doi.org/10.1016/S0967-0661(99)00112-4.

[23] Tamura, H. and Akazawa, K.: Structural modeling and systems analysis of uneasy factors for realizing safe, secure and reliable society. J. of Telecommunications and Information Technology, 3, 64-72, 2005.

[24] Gabus, A. and Fontela, E.: World Problems, An Invitation to Further Thought within the Framework of DEMATEL. Geneva: Battelle Geneva Research Centre, 1972.

[25] Gabus, A. and Fontela, E.: Perceptions of the World Problematique: Communication Procedure, Communicating with Those Bearing Collective Responsibility. Geneva: Battelle Geneva Research Centre, 1973.

[26] Fontela, E. and Gabus, A.: The DEMATEL Observer. Geneva: Battelle Geneva Research Centre, 1976.

[27] Falatoonitoosi, E., Leman, Z, Sorooshian, S. and Salimi, M.: Decision-making trial and evaluation laboratory. Research Journal of Applied Sciences, Engineering and Technology, 5(13), 3476-3480, 2013.

[28] Ding, J. F. and Liang, G. S.: Using fuzzy MCDM to select partners of strategic alliances for liner shipping. Information Sciences, 173, 197-225, 2005. https://doi.org/10.1016/j.ins.2004.07.013.

[29] Lee, Y. C., Hsieh, Y. F. and Guo, Y. B.: Construct DTPB model by using DEMATEL: A study of a university library website. Program, 47(2), 155-169, 2013. https://doi.org/10.1108/00330331311313744.

[30] Shahriari, M. R., Pilevari, N. and Gholami, Z.: The effect of information systems on the supply chain sustainability using DEMATEL method. Communications on Advanced Computational Science with Applications, 1, 47-56, 2016. https://doi.org/10.5899/2016/cacsa-00053.

[31] Hair Jr., J. F., Black, W. C., Babin, B. J. and Anderson, R. E.: Multivariate Data Analysis (7th ed.). US: Pearson Education Limited, 2013.

[32] Alderton, P. M.: Port Management and Operations. London: LLP, 1999.

[33] Canamero, C.: UNCTAD activities in the field of ports and their future. Maritime Policy and Management, 27(1), 65-70, 2000. https://doi.org/10.1080/030888300286699.

[34] Chow, H. K. H., Choy, K. L. and Lee, W. B. A.: dynamic logistics process knowledge-based system - An RFID multi-agent approach. Knowledge-Based Systems, 20(4), 357-372, 2007. https://doi.org/10.1016/j.knosys.2006.08.004.

[35] Ding, J. F. and Liang, G. S.: A study on developing international port logistics center in Taiwan: A viewpoint of integrated supply chain management. Journal of Maritime Sciences, 10, 99-119, 2002.

[36] Liang, G. S., Ding, J. F., and Chang, R. E.: Evaluating key capabilities for international port logistics centers: The application of fuzzy MCDM. Maritime Quarterly, 18(4), 19-44, 2009.

[37] Lu, C. S. and Yang, C. C.: Comparison of investment preferences for international logistics zones in Kaohsiung, Hong Kong, and Shanghai ports from a Taiwanese manufacturer's perspective. Transportation Journal, 45(1), 30-51, 2006.

[38] Notteboom, T. E. and Winkelmans, W.: Structural changes in logistics: How will port authorities face the change? Maritime Policy \& Management, 28(1), 71-89, 2001. https://doi.org/10.1080/03088830119197.

[39] Zadeh, L. A.: Fuzzy sets. Information and Contro8(3), 338-353, 1965. https://doi.org/10.1080/03088830119197

[40] Zadeh, L. A.: The concept of a linguistic variable and its application to approximate reasoning, Part 1, 2 and 3. Information Sciences, 8(3), 199-249, 1975; 8(4), 301-357, 1975; 9(1), 143-80, 1976.

Submitted: 24.07 .2017 .

Accepted: 03.11 .2017
Jiun-Yan Tsai

Department of Shipping and Transportation Management

National Taiwan Ocean University Keelung 20224, Taiwan

Ji-Feng Ding

Department of Aviation and Maritime Transportation Management

Chang Jung Christian University Tainan 71101, Taiwan

Gin-Shuh Liang, gsliang@mail.ntou.edu.tw

Department of Shipping and Transportation Management

National Taiwan Ocean University Keelung 20224, Taiwan

TEL: +886-2-24622192 ext. 3429 FAX: +886-2-24631903

Kung-Don Ye

Department of Shipping and Transportation Management

National Taiwan Ocean University Keelung 20224, Taiwan 